\title{
LETTER
}

\section{The solubility and oxidation state of nickel in silicate melt at low oxygen fugacities: Results using a mechanically assisted equilibration technique}

\author{
D. B. Dingwell, ${ }^{1}$ H. St .C. O'Neill, ${ }^{1}$ W. Ertel, ${ }^{\prime}$ and B. SPettel ${ }^{2}$ \\ 'Bayerisches Geoinstitut, Universität Bayreuth, 95440 Bayreuth, Germany \\ ${ }^{2}$ Max-Planck-Institut für Chemie, Postfach 3060, 55020 Mainz, Germany
}

(Received November 20, 1993; accepted in revised form February 10, 1994)

\begin{abstract}
The solubility of $\mathrm{Ni}$ in a silicate melt has been measured using a new, mechanically assisted equilibration technique over a wide range of controlled $f_{\mathrm{O}_{2}}$ values. The melt composition corresponds to the $1 \mathrm{~atm}$ eutectic in the system $\mathrm{CaAl}_{2} \mathrm{Si}_{2} \mathrm{O}_{8}-\mathrm{CaMgSi}_{2} \mathrm{O}_{6}+10 \mathrm{wt} \% \mathrm{CaO}$. The experiments were performed at $1300^{\circ} \mathrm{C}$ and over an $f_{\mathrm{O}_{2}}$ range of $10^{-8.5}$ to $10^{-13.75}$, and over a temperature range of 1270 to $1390^{\circ} \mathrm{C}$ at a constant gas mixing ratio $\left(\mathrm{CO}_{2} / \mathrm{CO}=1: 1\right)$. The experiment consists of a sample of melt contained within a crucible of $\mathrm{Ni}$ metal and held in a 1 atm gas mixing furnace. A Ni spindle is entered into the sample from above and continuously rotated at a constant angular velocity using a viscometer head. The stirring of the sample serves to accelerate the approach to equilibrium between the liquid sample and the metal crucible (and spindle). This arrangement allows relatively rapid equilibration of Ni content following changes to higher or lower $f_{\mathrm{O}_{2}}$ values. Samples of the melt may be taken at any time for analysis, and thus the equilibrium solubility of $\mathrm{Ni}$ in the silicate melt may be determined from unambiguous experimental reversals. The Ni contents of samples, analysed both by INAA and by ICP-AES, range from 25 to 5300 ppm.

The data presented in this paper indicate that the oxidation state of $\mathrm{Ni}$ in the investigated melt is $\mathrm{Ni}^{2+}$ over the entire range of $f_{\mathrm{O}_{2}}$ investigated. This conclusion contrasts with recent reports in the literature of an inflection in the $f_{\mathrm{O}_{2}}$ dependence of $\mathrm{Ni}$ solubility, which has been interpreted as solution of neutral $\mathrm{Ni}$ at low $f_{\mathrm{O}_{2}}$ (MORSE et al., 1991; COLSON, 1992; EHLERS et al., 1992). We also present data for the temperature dependence of $\mathrm{Ni}$ solubility in the investigated melt. The solubility decreases with increasing temperature at constant $f_{\mathrm{O}_{2}}$. The present results are in good agreement with the metal-loop-equilibration experiments reported by HOLZHEID et al. (1994).
\end{abstract}

\section{INTRODUCTION}

THERE HAVE RECENTLY BEEN several claims that substantial amounts (i.e., hundreds of parts per million) of neutral, zerovalent $\mathrm{Ni}\left(\mathrm{Ni}^{0}\right)$ dissolve in silicate melts (COLSON, 1992; EHLERS et al., 1992; MORSF et al., 1991). The geochemical implications of such a hypothesis are considerable: they include an explanation for the overabundance of $\mathrm{Ni}$ in the Earth's mantle (COLSON, 1992); and incompatible-element behavior of $\mathrm{Ni}$ at low (e.g., typical lunar) $f_{\mathrm{O}_{2}}$ (STEELE et al., 1992 ). In addition, unless $\mathrm{Ni}$ is totally anomalous, the postulated large zero-valent solubility of $\mathrm{Ni}$ implies that the zerovalent solubility of many other siderophile elements may greatly exceed their mantle abundances, and thus dominate their high temperature geochemical properties.

To address the possibility of zero-valent Ni solubility at low $f_{\mathrm{O}_{2}}$ we have employed a new experimental strategy for the collection of metal solubility data as a function of silicate melt composition, temperature, and $f_{\mathrm{O}_{2}}$. The method consists of equilibrating in a gas-mixing furnace a relatively large amount $(100 \mathrm{~g})$ of silicate melt, which is held in a crucible made from the metal of interest (e.g., here Ni). The melt is continuously stirred by a spindle of the same metal. The $f_{\mathrm{O}_{2}}$ of the experiment is controlled using conventional gas mixing techniques. Samples may be withdrawn from the cru- cible for analysis at any time. The method permits the monitoring of changes in metal solubility as a time series after changing $f_{\mathrm{O}_{2}}$, temperature, or melt composition. This provides a means by which attainment of equilibrium may be tested. Reversals of the equilibrium with respect to either oxygen fugacity or temperature may be performed, all during a single experimental run. The amount of sample withdrawn for analysis is of the order of $0.5 \mathrm{~g}$, which permits the use of a wide variety of analytical methods, including those most suited for the determination of part per million abundances of the element in question. The result is a very precise determination of the dependence of Ni solubility on $f_{\mathrm{O}_{2}}$ over a wide range of these variables.

\section{METHOD}

\section{Experimental}

Several $80 \mathrm{~g}$ batches of a haplobasaltic composition in the system $\mathrm{CaO}-\mathrm{MgO}-\mathrm{Al}_{2} \mathrm{O}_{3}-\mathrm{SiO}_{2}$ were prepared from analytical grade $\mathrm{MgO}$, $\mathrm{Al}_{2} \mathrm{O}_{3}, \mathrm{SiO}_{2}$, and $\mathrm{CaCO}_{3}$, all chemicals were predried at $300^{\circ} \mathrm{C}$ $\left(\mathrm{CaCO}_{3}\right)$ or $1000^{\circ} \mathrm{C}$. In addition, $100 \mathrm{~g}$ of a gel of similar composition was prepared by the usual methods containing $12.2 \mathrm{mg} \mathrm{Sc}_{2} \mathrm{O}_{3}$, so that the Sc could act as a monitor of analytical quality during the subsequent neutron activation analyses. $5 \mathrm{~g}$ of this gel mixture was added to each batch. 
These mixtures were dried and fused in high density alumina crucibles (Friedrichsfeld $\mathrm{AL} 23^{\mathrm{TM}}$ ) in a $\mathrm{MoSi}_{2}$ box furnace at $1400^{\circ} \mathrm{C}$ for 30-60 min. The samples with crucibles were removed from the furnace and allowed to cool in air. The samples were then broken out of the alumina crucibles with a hammer and loaded as chips ( 25 g) into a Ni crucible at $1300^{\circ} \mathrm{C}$ and a low starting value of $f_{O_{2}}$ ( see Results section).

The experimental set-up for the solubility determinations is illustrated schematically in Fig. 1 . The $\mathrm{Ni}$ crucible with sample rests on a hollow alumina pedestal in the hot zone of a vertical gas-mixiny furnace within an alumina muffle tube, which is held at the top and the bottom by water cooling jackets.

For most of the work reported in this paper, the $f_{\mathrm{O}_{2}}$ was imposed using $\mathrm{CO} / \mathrm{CO}_{2}$ gas mixtures. $\mathrm{CO}$ and $\mathrm{CO}_{2}$ gas flow rates were controlled using Tylan FC $280 S$ mass flow controllers $\left(0-300 \mathrm{~cm}^{3} / \mathrm{s}\right)$, operated electronically from a Tylan RO-7020/7021 ${ }^{\mathrm{TM}}$ multi-channel read-out system. The $f_{\mathrm{O}_{2}}$ was continuously monitored for most of the experiment using a $\mathrm{SIRO}_{2}{ }^{\mathrm{TM}}$ yttria-stabilized zirconia oxygen sensor, which was placed immediately below the crucible in the hot zone of the furnace. Slots are cut in the pedestal tube to facilitate gas circulation between sample and electrode. As a preliminary check of the system, the $f_{\mathrm{O}_{2}}$ in an empty crucible was checked using a second

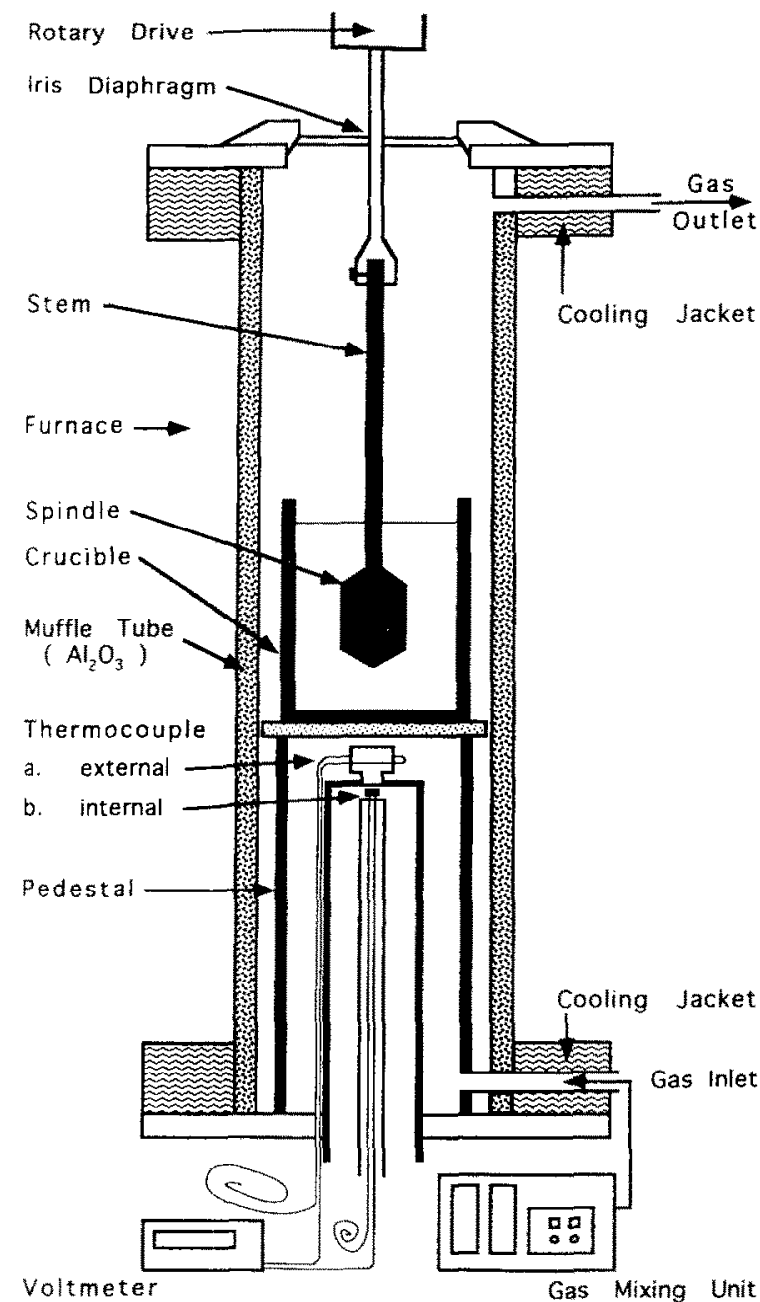

FIG. 1. Schematic illustration of the experiment used to determine the solubility of $\mathrm{Ni}$ in a silicate melt. The silicate melt is contained in a crucible of the metal to be dissolved and stirred by a spindle of the same metal. The $f_{\mathrm{O}_{2}}$ is controlled by gas mixtures and monitored by a solid electrolyte cell. The samples are removed with a dip stick through the top of the furnace. See text for further details. oxygen sensor lowered from the top of the furnace, and compared with that measured by the permanent electrode below the crucible. The ranges of gas flow rates and $f_{\mathrm{O}_{2}}$ was determined for which no significant difference in $f_{O_{2}}\left(\log f_{O_{3}}\right.$ within $0.03 \mathrm{log}$-bar units) between the two oxygen sensors was observable.

The temperature inside the muffle tube is measured on both sides of the oxygen electrode during the experiment using type B Pt/Rh thermocouples. The type B thermocouples were chosen over the more often used type $S$ or $R$ because they are mechanically stronger at higher temperature, and less liable to break. This is an important experimental consideration given the long duration of the experiment. The temperature typically varies by less than $\pm 2{ }^{\circ} \mathrm{C}$ over long periods of time (months) during gas mixing experiments.

To start the experiment, the Ni crucible is nearly filled with chips of prepared glass during an initial fusion in the crucible under low $f_{\mathrm{O}_{2}}$, and a $\mathrm{MgO}$ collar is placed on the rim of the crucible to prevent accidental contact between the crucible and the spindle. We found during the early stages of the experiment that even brief contact between crucible and spindle causes them to stick fast together, necessitating the experiment to be cooled down to room temperature, and the crucible plus spindle to be removed and then separated. The $\mathrm{Ni}$ spindle is hung from a viscometer head (Brookfield RVTD) by a series of stainless steel segments, which pass into the muffle tube through a centered iris diaphragm in the top water-cooled jacket. The iris may be opened to the desired extent for access to the crucible during the initial loading and spindle insertion, and the subsequent sample extractions. During equilibration/stirring the iris is closed down to the size of the stainless steel stirring segment. The entire length of the Ni spindle and its Ni stem are kept within the controlled atmosphere in the alumina muffle tube, and never come into contact with air at elevated temperatures. Thus, surface oxidation is prevented.

The Ni spindle is lowered into the melt through the $\mathrm{MgO}$ collar and to a position a few millimeters above the $\mathrm{Ni}$ crucible floor using a lab stand with a rack-and-pinion mechanism. In this way the vertical positioning of the spindle is reproducible. The samples are stirred at $10-100 \mathrm{rpm}$ depending on viscosity.

As noted above, the strategy of the experiment is to afford maximum flexibility in choosing the successive steps of equilibration and sampling. Changes in $f_{\mathrm{O}_{2}}$, in temperature and (in ongoing work which will be reported later) in composition can all be made in a stepwise fashion, and since samples can be taken at any time, the approach to constant state (implying equilibrium) may thus be monitored. Figure 2 illustrates the time- $f_{\mathrm{O}_{2}}$ path of the experiment reported here. The $f_{2}$ is changed stepwise by selecting a different gas mixing ratio, following which the response time of the system is a few minutes, as monitored by the oxygen sensors. The entire $f_{2}$ history of the experiment is recorded on a chart recorder. Since previous experience with Ir solubility experiments (O'NEILL et al., 1993, 1994) had shown us that equilibrium was reached many times faster on increasing than on decreasing $f_{\mathrm{O}_{2}}$, the strategy adopted here was to hegin the experiment at low $f_{\mathrm{O}_{2}}$, and then increase $f_{0}$ in successive steps. The experiment was then reversed by decreasing $f_{O_{2}}$. (However, the results from this experiment show that the kinetics of Ni solution, are quite different from those of Ir. In hindsight, it would have been preferable to conduct the experiment the other way round.)

Some authors have speculated that the gases used to control $f_{\mathrm{O}_{2}}$ may influence $\mathrm{Ni}$ solubilities (COLSON, 1992; CAPOBIANCO and AMELIN, 1994). In order to test this hypothesis, and to fix $f_{\mathrm{O}_{2}}$ at lower values than is possible with $\mathrm{CO} / \mathrm{CO}_{2}$ gas mixtures, we have also used $\mathrm{H}_{2} / \mathrm{H}_{2} \mathrm{O}$ mixtures. Pure $\mathrm{H}_{2}$ and a $90 \% \mathrm{~N}_{2}-10 \% \mathrm{H}_{2}$ ( forming gas) was bubbled through an ice/water mixture contained in a Dewar flask. The ice/ water mixture should control $\mathrm{pH}_{2} \mathrm{O}$ at $6.1 \mathrm{mbar}$. How ever, for the $\mathrm{N}_{2}-\mathrm{H}_{2}$ mixture, the oxygen sensor gave a stable e.m.f. indicating $\log f_{\mathrm{O}_{2}}=-11.80$, constant over the time of this segment of the experiment (which lasted for 14 days). This corresponds to a $\mathrm{pH}_{2} \mathrm{O}$ of $25.9 \mathrm{mbar}$, the vapour pressure above water at $21^{\circ} \mathrm{C}$, i.e., room temperature. We believe, therefore, that water vapour condensation in our apparatus fixed $\mathrm{pH}_{2} \mathrm{O}$ at this level. For the mixture with pure $\mathrm{H}_{2}$, the oxygen sensor briefly gave a reading corresponding to $\log f_{\mathrm{O}_{2}}=-13.75$, which is precisely that expected for $\mathrm{pH}_{2} \mathrm{O}=25.9$ mbar. However, the sensor then expired from loss of electrical contact after several minutes of operation. Subsequent examination revealed that the high $\mathrm{Rh}$ leg of the thermocouple, which also acts as the 
external lead wire, appeared to have melted, suggesting that Rh-rich Rh-Pt alloys may absorb appreciable $\mathrm{H}_{2}$.

The melts were sampled by stopping the stirring, raising the $\mathrm{Ni}$ spindle to a point just above the $\mathrm{MgO}$ collar, opening the iris, and dipping an alumina rod ( $3 \mathrm{~mm}$ diameter) into the liquid surface. A drop of melt (typically $0.5 \mathrm{~g}$ ) congeals around the cool rod. The rod was quickly removed from the furnace, the iris closed, and the rod plunged into distilled water in a beaker. The spindle was lowered back to a position immediately above the melt surface, allowed to thermally equilibrate for 5-10 min, and then lowered into the melt and the stirring resumed.

\section{Analysis}

Concentrations of $\mathrm{Ni}$ in the samples of quenched melt were analysed at the Bayerisches Geoinstitut in Bayreuth using a ISA-JobinYvon JY 24 sequential Inductively Coupled Plasma-Atomic Emission Spectrometer. Samples were prepared by grinding, overnight drying at $110^{\circ} \mathrm{C}$ and dissolution in $40 \% \mathrm{HF}$. $\mathrm{CaF}_{2}$ precipitate was dissolved using concentrated $\mathrm{H}_{3} \mathrm{BO}_{3}$. To these solutions were added $50 \mathrm{ppm}$ of yttrium to serve as an internal standard. The samples were then measured immediately. The ICP-AES was calibrated with 4 single element standard solutions of differing Ni contents. The theoretical accuracy of the analyses is $2 \%$ relative.

Concentrations of $\mathrm{Ni}$ were analysed at Mainz by instrumental neutron activation analysis (INAA). For INAA irradiations were performed at the TRIGA-reactor of the Institut für Kernchemie at the Johannes-Gutenberg-Universität Mainz, Germany. The neutron flux was $7 \times 10^{11} \mathrm{n} \mathrm{cm}^{-2} \mathrm{sec}^{-1}$ and duration of radiation $6 \mathrm{~h}$. Samples were counted on large volume $\mathrm{Ge}(\mathrm{Li})$-detectors. Decay of ${ }^{58} \mathrm{Co}$ ( for $\mathrm{Ni}, 810.5 \mathrm{keV}, T_{1 / 2}=71 d$ ) was registered. All samples were counted at least twice. Scandium activities $\left({ }^{46} \mathrm{Sc}, 889.2 \mathrm{KeV}\right.$ and $1120.6 \mathrm{KeV}$, $T_{1 / 2}=84 d$ ) were simultaneously recorded and used as monitors for INAA procedures.

A comparison of the results from the two analytical methods is given in Fig. 3 and is included in Table 1. The INAA results appear to give slightly higher values at lower concentrations but all samples agree within -10 to $+35 \%$, except one $(\mathrm{Ni}-1-40)$ for which the ICP analysis is anomalously low. Excluding this sample, the mean deviation difference between the two methods is $12 \%$.

The major element composition of the starting material and of several samples was determined by electron microprobe analysis at the Bayerisches Geoinstitut. The operating conditions were $15 \mathrm{kV}$ accelerating voltage, $15 \mathrm{nA}$ current on brass, $20 \mathrm{~s}$ count times, and a defocussed beam. The standards were wollastonite $(\mathrm{Ca})$, enstatite $(\mathrm{Mg})$, spinel $(\mathrm{Al})$, and orthoclase $(\mathrm{Si})$. The composition (normalized to $100 \%$ ) in weight percent is $26.6 \% \mathrm{CaO}, 10.7 \% \mathrm{MgO}, 15.3 \% \mathrm{Al}_{2} \mathrm{O}_{3}$, and $47.4 \% \mathrm{SiO}_{2}$. There was no drift of composition during the course of the experiment.

\section{RESULTS AND DISCUSSION}

\section{Kinetics}

Sampling at each condition of $f_{\mathrm{O}_{2}}$ has been performed in a time series. An example of data for these time series is presented in Fig. 4, where it is evident that the time required to reach a steady state after lowering $f_{\mathrm{O}_{2}}$ (and Ni solubility) is shorter than after raising $\int_{\mathrm{O}_{2}}$. The higher rate of equilibration in the direction of decreasing $\mathrm{Ni}$ content is consistent with the observation made during similar experiments involving the reduction of $\mathrm{Fe}$ in Fe-rich melts (DINGWELL and VIRGO, 1987), i.e., the rate of reduction was observed to be much higher than the rate of oxidation. The explanation proposed at that time was that the reduction proceeds by generation of oxygen gas, which forms bubbles which are easily liberated from the melt. The oxidation of the same melt requires diffusive transport of oxygen. Although this is assisted in these experiments by forced convection, this latter process should still be slower than the former. This asymmetry in the kinetics is in the opposite sense to that observed by us for oxidation and reduction of Ir-bearing melts (O'NEILL et al., 1993, 1994), where the rate of decrease of Ir concentration on lowering $f_{\mathrm{O}_{2}}$ is orders of magnitude slower than the rate of increase on raising $f_{\mathrm{O}_{2}}$. The indication is that a quite different mechanism controls the rate of reduction in the Ir experiments. This mechanism may be related to differences in the absolute concentration ranges of the dissolved metals (ppm in the Ni experiment, ppb in the Ir study), or to differing surface properties of the metals affecting particle suspension properties at high temperatures. An understanding of these kinetics may be important for the interpretation of other metal solubility studies, and warrants further investigation.

\section{$f_{\mathrm{O}_{2}}$ and Temperature Dependence of Nickel Solubility}

The analysed $\mathrm{Ni}$ contents of our samples (from both INAA and ICP-AES), together with the $f_{\mathrm{O}_{2}}$ derived from oxygen specific electrode measurements, the elapsed time of the experiment and the temperature, are presented in Table 1. As noted above, the sequence of the experimental conditions is also graphically portrayed in Fig. 2. The experiment began with an equilibration at very low $f_{\mathrm{O}_{7}}$ and $1300^{\circ} \mathrm{C}$ using the lowest $\mathrm{CO}_{2} / \mathrm{CO}$ ratio at which a nearly stable $f_{\mathrm{O}_{2}}$ as measured by the sensor, could be empirically obtained. The flow rate of $\mathrm{CO}_{2}$ in this mixture was below the calibration threshold of the mass flow controllers. The $f_{\mathrm{O}_{2}}$ was increased stepwise by changing the $\mathrm{CO}_{2} / \mathrm{CO}$ ratio up to the highest value of $f_{\mathrm{O}_{2}}$ investigated here. Next the $f_{\mathrm{O}_{2}}$ was reduced to provide a reversal. The experiment was then switched to the $\mathrm{N}_{2}-\mathrm{H}_{2}-$ $\mathrm{H}_{2} \mathrm{O}$ mixture, and then further reduced to an extremely low value using the pure $\mathrm{H}_{2}-\mathrm{H}_{2} \mathrm{O}$ mix. Finally, the $f_{\mathrm{O}_{2}}$ was increased again in preparation for investigation of the temperature dependence of solubility. The temperature dependence was determined during stepwise increase of the temperature from 1270 to $1390^{\circ} \mathrm{C}$ at $30^{\circ} \mathrm{C}$ intervals, at constant gas mixing ratio $\left(\mathrm{CO}_{2} / \mathrm{CO}=1\right)$.

The information on the rate of approach to equilibrium from the time series at constant $f_{\mathrm{O}_{2}}$ (e.g., Fig. 4) indicates that, especially during the earlier part of the experiment, equilibrium solubility of $\mathrm{Ni}$ at $1300^{\circ} \mathrm{C}$ should be approached but not quite attained. Our results thus consist of reversals brackets, which constrain the equilibrium solubility of $\mathrm{Ni}$ to lie either above them (increasing $f_{\mathrm{O}_{2}}$ ) or below them (decreasing $f_{\mathrm{O}_{2}}$ ). This is illustrated in Fig. 5 .

The equilibrium solubility of $\mathrm{Ni}$ in a silicate melt of fixed composition may be described by the expression

$\log (\mathrm{Ni}$ solubility in $\mathrm{ppm})$

$$
=x \log f_{\mathrm{O}_{2}}+C_{1} / T(\mathrm{~K})+C_{2},
$$

where $x$ is the formal valence of $\mathrm{Ni}$ in the melt, according to the balanced chemical reaction

$$
\mathrm{Ni}_{\text {(metal) }}+x / 4 \mathrm{O}_{2}=\mathrm{Ni}_{x / 2} \mathrm{O}_{\text {(melt) }} \text {. }
$$

Thus, $x$ may be determined from the slope of a plot of log ( $\mathrm{Ni}$ solubility in ppm) vs. $\log f_{\mathrm{O}_{2}}$. As shown in Fig. 5, our data can be well fitted using $x=2$; that is, assuming $\mathrm{Ni}$ dissolves only in the silicate melt as $\mathrm{Ni}^{2+}$. There is no necd to postulate the existence of any zero-valent $\mathrm{Ni}\left(\mathrm{Ni}^{0}\right)$ dissolved in the melt. In fact, the minimum slope which still 

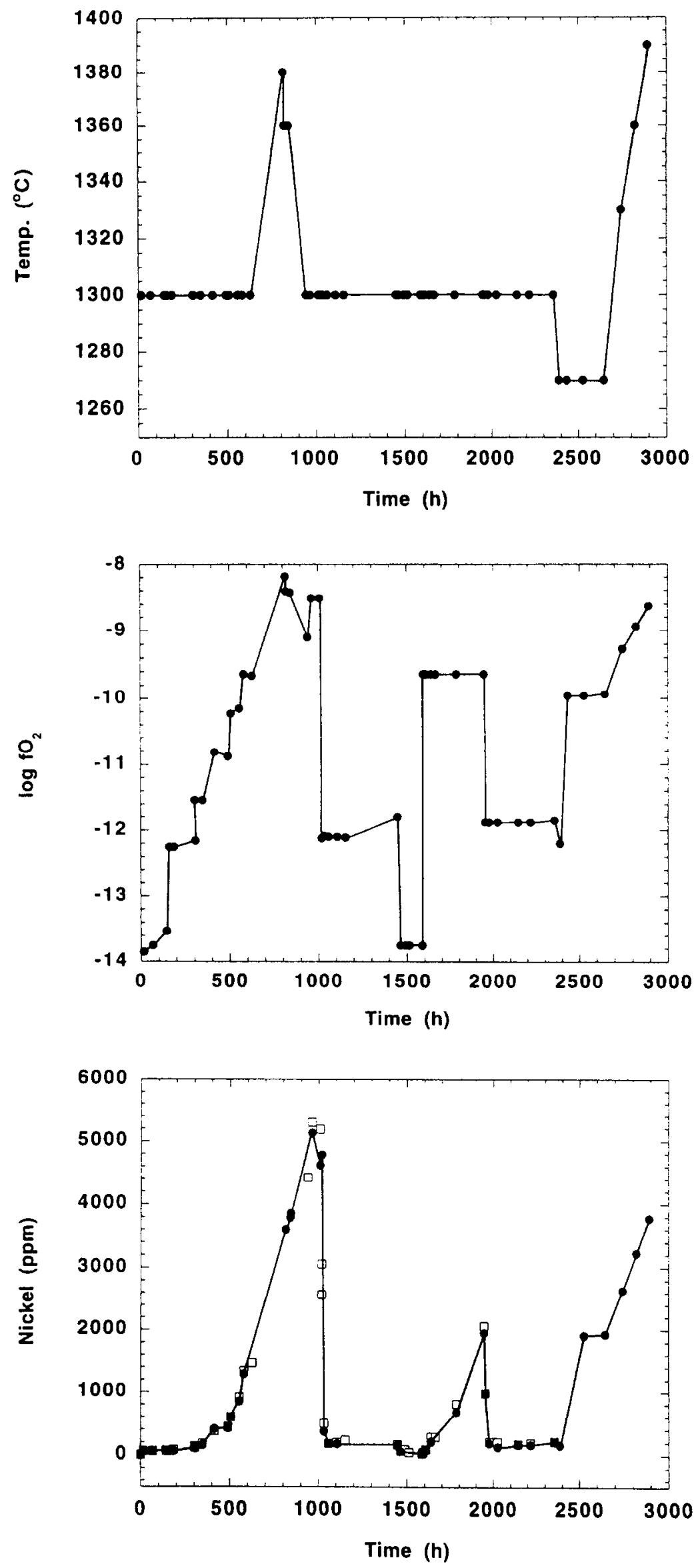
satisfies the reversal brackets is 0.46 , and the maximum amount of $\mathrm{Ni}^{0}$ is constrained to be less than $\sim 10 \mathrm{ppm}$.

The temperature dependence of the solubility of $\mathrm{Ni}$ is presented in Fig. 6a where the experimental data obtained at a constant $\mathrm{CO} / \mathrm{CO}_{2}$ ratio of 1 are shown. A combined fit of these data and the reversal brackets of Fig. 5 to an expression with the form of Eqn. 1, assuming $x=0.5$, gives

$\log (\mathrm{Ni}$ solubility in $\mathrm{ppm})$

$$
=0.5 \log f_{\mathrm{O}_{2}}+7670 / T(\mathrm{~K})+3.28,
$$

with an estimated accuracy of \pm 0.05 in $\log \mathrm{Ni}$ (equivalent to $\pm 12 \%$ in $\mathrm{Ni}$ ) over most of the $T-f_{\mathrm{O}_{2}}$ range covered by the experiment.

Note that the solubility of $\mathrm{Ni}$ decreases at constant $f_{\mathrm{O}_{2}}$ with increasing temperature, implying that, at constant $f_{\mathrm{O}_{2}}$, the partition coefficient of $\mathrm{Ni}$ between metal and silicate melt ( $D_{\mathrm{Ni}}^{\text {met }}$ sil melt $)$ will increase with increasing temperature.

Our results are in essentially perfect agreement with those of HOLZHEID et al. (1994) for a anorthite-diopside eutectic composition at higher $f_{\mathrm{O}_{2}}$ values as shown in Fig. 5. At lower $f_{\mathrm{O}_{2}}$ values we infer slightly lower solubilities, which provide tighter constraints on the maximum amount of $\mathrm{Ni}^{\circ}$. The temperature dependence of the Ni solubility in Eqn. 3 is also the same as that found by Hol.7.HFID et al. (1994).

These data are compared with data for $\mathrm{Ni}$ solubility reported by COLSON (1992) in a melt of the 1 atm eutectic in the system $\mathrm{CaAl}_{2} \mathrm{Si}_{2} \mathrm{O}_{8}-\mathrm{CaMgSi}_{2} \mathrm{O}_{6}$ at $1400^{\circ} \mathrm{C}$ and in a similar range of $f_{\mathrm{O}_{2}}$ (Fig. 5). At high $f_{\mathrm{O}_{2}}$ both studies concur in the observation of a slope corresponding to the solution of $\mathrm{Ni}$ almost entirely as $\mathrm{Ni}^{2+}$. At low $f_{\mathrm{O}_{2}}$, the results of COLSON (1992) deviate from this trend towards a lower slope value; a smaller dependence of $\mathrm{Ni}$ content on $f_{\mathrm{O}_{2}}$. COLSON (1992) interpreted this trend as resulting from the presence of neutral $\mathrm{Ni}\left(\mathrm{Ni}^{0}\right)$ dissolved in these melts at low $f_{\mathrm{O}_{2}}$. Our data show no such deviation from the behavior expected of $\mathrm{Ni}$ dissolved in the divalent $\left(\mathrm{Ni}^{2+}\right)$ state to the lowest values of $f_{\mathrm{O}_{2}}$ that we have been able to obtain. The amount of $\mathrm{Ni}^{0}$ expected at $1300^{\circ} \mathrm{C}$ from Eqn. 6 of COLSON (1992) would be 300 ppm.

How can we explain the difference between our results and those of COLSON (1992)? In his interpretation of his experimental observations, Colson supposed that the apparent decrease of $\mathrm{Ni}$ as analysed by the electron microprobe away from the Ni metal-silicate glass interface was due to continuous volatile loss of $\mathrm{Ni}$ from the silicate melt. In fact, thermodynamic data for possible Ni gas species (BARIN, 1989including $\mathrm{Ni}$ carbonyls, which are only stable at low temperatures) reveal no tendency for any appreciable Ni volatility. In agreement with this expectation, we observe absolutely no evidence for any $\mathrm{Ni}$ volatility in our experiment, even after $3000 \mathrm{~h}$ under conditions similar to those used in the experiments of COLSON 1992; in which drastic loss of $\mathrm{Ni}$ is claimed to be observable in a matter of minutes. The possibility needs to be entertained that the "diffusion profiles"

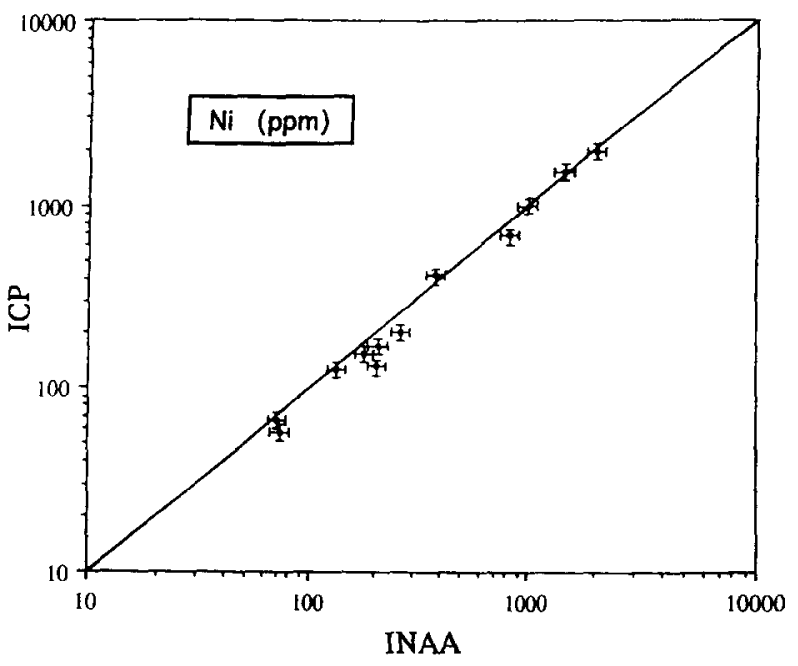

FIG. 3. A comparison of the analytical data for $\mathrm{Ni}$ determined by ICP-AES (Bayreuth) and INAA (Mainz).

of COLSON ( 1992) are analytical artifacts caused by secondary $\mathrm{X}$-ray fluorescence and the proximity of the Ni metal, as has recently been experimentally demonstrated to operate over comparable distances by CAPOBIANCO and AMELIN (1994; see their Fig. 1). The true levels of $\mathrm{Ni}$ in the experiments of COLSON (1992) may simply be those found more than 200 $\mu$ from the metal interface.

Other possible explanations for higher than expected levels of $\mathrm{Ni}$ or other siderophile elements in silicate melts at low $f_{\mathrm{O}_{2}}$, which could give rise to thoughts of neutral metal species, are

1) Very small particles of metal may be stranded by suspension in the melt, and unable to settle out on normal experimental timescales. Here we hope that the mechanical stirring which sets up a forced convective regime in the liquid sweeps metal particles to the crucible walls. When attempting to measure the solubility of metals at very low levels, it is also important to demonstrate reversal of the equilibrium not only by starting with high and low levels of the metal in the melt, but also by demonstrating that the steady state is actually being approached from the high and low levels. The ability to do this by taking samples in a time series is perhaps the principal strength of the experimental method described here. The need for this kind of demonstration would be particularly important if there is asymmetry in the rates of increase and decrease of metal concentrations (as found for Ir; e.g., see O'NEILl et al., 1993, 1994): if the rate of increasing metal concentration is rapid, absorbed oxygen in the starting materials may produce significant levels of the metal in the melt initially, even in nominally metal-free

FIG. 2. The sequence of events in the $\mathrm{Ni}$ solubility experiment. Temperature, $f_{\mathrm{O}_{2}}$ fugacity, and analysed $\mathrm{Ni}$ content are plotted vs. time. The experiment began at $1300^{\circ} \mathrm{C}$ under very reducing conditions. The $f_{\mathrm{O}_{2}}$ was systematically increased in a stepwise fashion and the melt was continually sampled. Reversals in the Ni contents were achieved through subsequent reduction of the $f_{\mathrm{O}_{2}}$. Finally the $f_{\mathrm{O}_{2}}$ was held constant at the temperature was varied. See text for more details. 


\section{Table 1. Experimental Results}

\begin{tabular}{|c|c|c|c|c|c|c|c|c|}
\hline $\begin{array}{c}\text { Sample } \\
\mathrm{Nr} .\end{array}$ & $\begin{array}{c}\text { Time } \\
(h)\end{array}$ & $\begin{array}{c}\text { Temp. } \\
\left({ }^{\circ} \mathrm{C}\right)\end{array}$ & $\begin{array}{l}\mathrm{CO}_{2} \\
(\%)\end{array}$ & $\underset{f=1}{\log \mathrm{fO}_{2}}$ & $\begin{array}{c}\text { emt } \\
(m v)\end{array}$ & $\begin{array}{c}\log \mathrm{fO}_{2} \\
\text { (b) }\end{array}$ & $\begin{array}{c}\text { Ni INAA } \\
\text { (ppm) }\end{array}$ & $\begin{array}{l}\text { Ni ICP } \\
\text { (ppm) }\end{array}$ \\
\hline 1 & 16 & 1300 & $<5$ & & 1028 & .13 .85 & 64 & 67 \\
\hline 2 & 66 & 1300 & $<5$ & & 1020 & -13.75 & 62 & 57 \\
\hline 3 & 143 & 1300 & $<5$ & & 1003 & .13 .53 & 73 & 57 \\
\hline 4 & 159 & 1300 & 5 & .12 .28 & 903 & -12.25 & 68 & 59 \\
\hline $5^{\circ}$ & 184 & 1300 & 5 & -12.28 & 903 & -12.25 & 82 & 63 \\
\hline 6 & 304 & 1300 & 5 & -12.28 & 896 & -12.16 & 114 & 102 \\
\hline 7 & 302 & 1300 & 10 & -11.63 & 848 & .11 .55 & 134 & 127 \\
\hline $8^{\circ}$ & 346 & 1300 & 10 & .11 .63 & 848 & -11.55 & 180 & 154 \\
\hline $9^{*}$ & 414 & 1300 & 20 & .10 .93 & 791 & .10 .82 & 380 & 410 \\
\hline 10 & 490 & 1300 & 20 & -10.93 & 796 & .10 .88 & 440 & 420 \\
\hline 11 & 506 & 1300 & 35 & -10.26 & 745 & .10 .23 & 600 & 600 \\
\hline 12 & 554 & 1300 & 35 & -10.26 & 739 & -10.15 & 920 & 850 \\
\hline 13 & 579 & 1300 & 50 & -9.72 & 699 & -9.64 & 1340 & 1290 \\
\hline $14^{*}$ & 626 & 1300 & 50 & .9 .72 & 701 & -9.66 & 1470 & \\
\hline 15 & 814 & 1380 & 67 & -8.19 & 616 & -8.19 & & 3600 \\
\hline 16 & 819 & 1360 & 67 & .8 .43 & 626 & -8.41 & & \\
\hline 17 & 840 & 1360 & 67 & .8 .43 & 628 & .8 .43 & & 3790 \\
\hline $18^{\circ}$ & 843 & 1360 & 67 & -8.43 & 628 & .8 .43 & & 3860 \\
\hline 19 & 939 & 1300 & 67 & -9.11 & 657 & -9.10 & 4430 & \\
\hline 20 & 961 & 1300 & 80 & .8 .52 & 611 & -8.51 & 5300 & 5130 \\
\hline 21 & 1008 & 1300 & 80 & -8.52 & 611 & -8.51 & 5190 & 4620 \\
\hline $22 a$ & 1018 & 1300 & 5 & -12.28 & 893 & -12.12 & 2570 & 4790 \\
\hline 220 & 1018 & 1300 & 5 & .12 .28 & 893 & -12.12 & 3060 & \\
\hline 23 & 1033 & 1300 & 5 & .12 .28 & 890 & -12.09 & 500 & 370 \\
\hline 24 & 1058 & 1300 & 5 & .12 .28 & 891 & -12.10 & 182 & 182 \\
\hline 25 & 1106 & 1300 & 5 & -12.28 & 891 & .12 .10 & 200 & 178 \\
\hline 26 & 1153 & 1300 & 5 & .12 .28 & 892 & -12.11 & 240 & \\
\hline $27 a$ & 1447 & 1300 & (c) & & 868 & -11.80 & 163 & \\
\hline 270 & 1447 & 1300 & (c) & & 868 & -11.80 & 173 & 162 \\
\hline 28 & 1464 & 1300 & (d) & & 1020 & -13.75 & 71 & 67 \\
\hline 29 & 1491 & 1300 & (d) & & & & 96 & \\
\hline 30 & 1513 & 1300 & (d) & & & & 50 & \\
\hline 31 & 1587 & 1300 & (d) & & & & 32 & 25 \\
\hline 32 & 1594 & 1300 & 50 & .9 .72 & & & 52 & 39 \\
\hline 33 & 1608 & 1300 & 50 & .9 .72 & & & 94 & 92 \\
\hline $34 a$ & 1638 & 1300 & 50 & .9 .72 & & & 270 & 210 \\
\hline $34 b$ & 1638 & 1300 & 50 & -9.72 & & & 290 & 220 \\
\hline 35 & 1663 & 1300 & 50 & .9 .72 & 699 & -9.64 & 290 & \\
\hline 36 & 1783 & 1300 & 50 & .9 .72 & & & 820 & 680 \\
\hline 37 & 1946 & 1300 & 50 & -9.72 & & & 2060 & 1950 \\
\hline 38 & 1954 & 1300 & 5 & .12 .28 & & & 990 & 990 \\
\hline 39 & 1977 & 1300 & 5 & .12 .28 & & & 210 & 192 \\
\hline 40 & 2025 & 1300 & 5 & .12 .28 & & & 210 & 131 \\
\hline 41 & 2144 & 1300 & 5 & .12 .28 & & & 180 & 170 \\
\hline 42 & 2217 & 1300 & 5 & .12 .28 & 874 & .11 .88 & 194 & 170 \\
\hline 43 & 2355 & 1300 & 5 & .12 .28 & 872 & .11 .85 & 220 & 210 \\
\hline 44 & 2386 & 1270 & 5 & .12 .64 & 882 & -12.20 & & 158 \\
\hline 45 & 2432 & 1270 & 50 & $: 10.09$ & 710 & .9 .96 & & \\
\hline 46 & 2526 & 1270 & 50 & -10.09 & 710 & .9 .96 & & 1910 \\
\hline 47 & 2645 & 1270 & 50 & -10.09 & 709 & .9 .94 & & 1930 \\
\hline 48 & 2742 & 1330 & 50 & -9.38 & 683 & -9.27 & & 2640 \\
\hline 49 & 2818 & 1360 & 50 & .9 .04 & 669 & -8.94 & & 3230 \\
\hline 50 & 2890 & 1390 & 50 & .8 .72 & 656 & -8.63 & & 3780 \\
\hline
\end{tabular}

(a) calculated from the gas mixing ratio

(b) calculated from the oxygen sensor emf

(c) $\quad \mathrm{H}_{2} \mathrm{O}-\mathrm{H}_{2}-\mathrm{N}_{2}$

(d) $\quad \mathrm{H}_{2} \mathrm{O}-\mathrm{H}_{2}$

* Experiment was temporarily interrupted after these samples were taken, and then restarted 

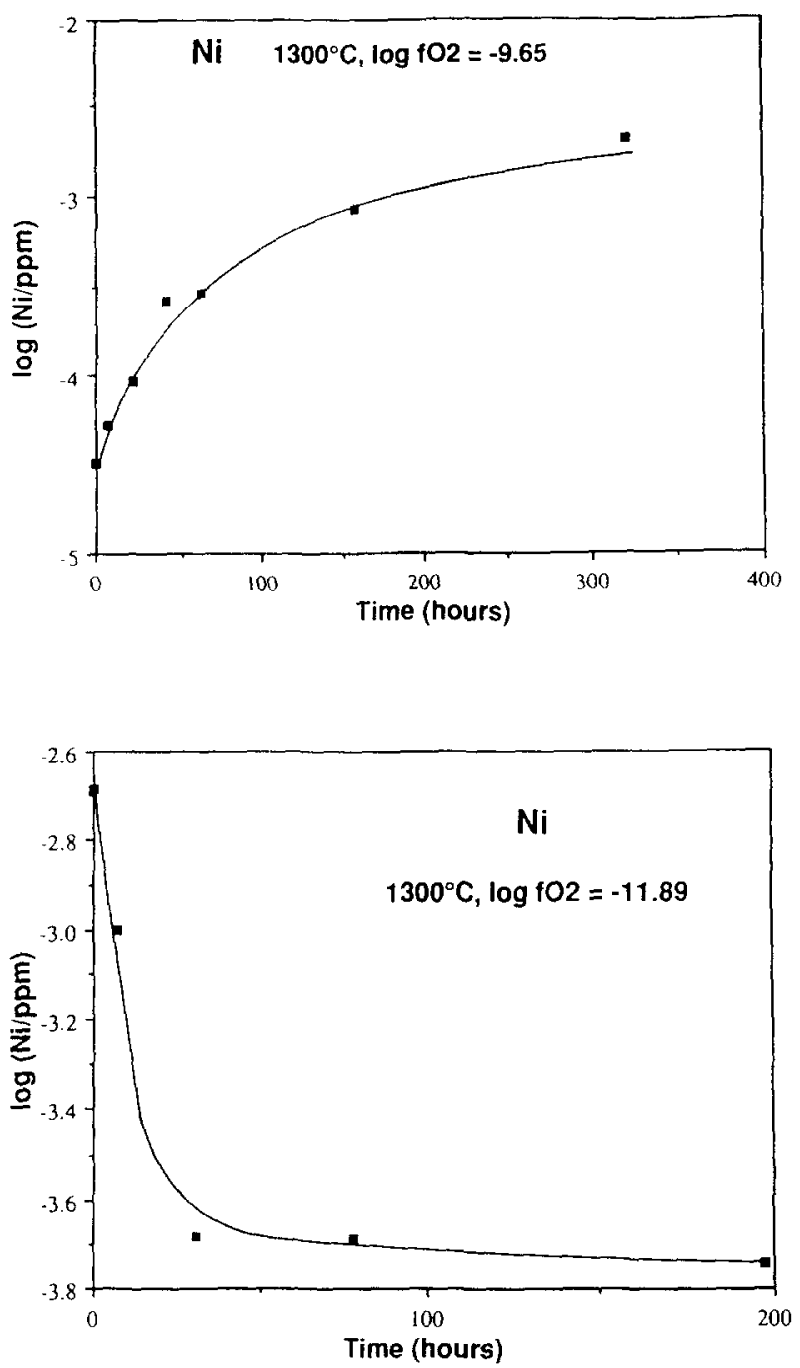

FIG. 4. The approach to equilibrium in Ni content for melts undergoing oxidation and reduction. The oxidation proceeds much more slowly than the reduction (note the different scales).

silicate, which may then not decrease during the timescale of the experiment.

2) Very low $f_{\mathrm{O}_{2}}$ conditions are difficult to produce experimentally using C-based gas mixtures, not least because graphite precipitation in the cooler parts of the furnace may alter the composition of the mixture. $\mathrm{I}_{2}$-rich $\mathrm{CO}_{2}$ $\mathrm{H}_{2}$ gases may fail to equilibrate at high flow rates, and are liable to unmixing at low flow rates from thermal diffusion (HUEBNER, 1987). Electrochemical oxygen sensors provide some safeguard against these potential pitfalls, but may perhaps not be infallible. Their response is catalysed by their Pt surface, and could thus record the expected $f_{\mathrm{O}_{2}}$ for the gas mixture, whereas the $f_{\mathrm{O}_{2}}$ actually experienced by the rest of the experiment might be modified by processes such as carbon precipitation or unmixing operating over longer timescales. Here we have guarded against such difficulties by also using $\mathrm{H}_{2}-\mathrm{H}_{2} \mathrm{O}$ mixtures.

3) Attempting chemical analyses with a method near to its limit of detection is fraught with difficulty, and often re-

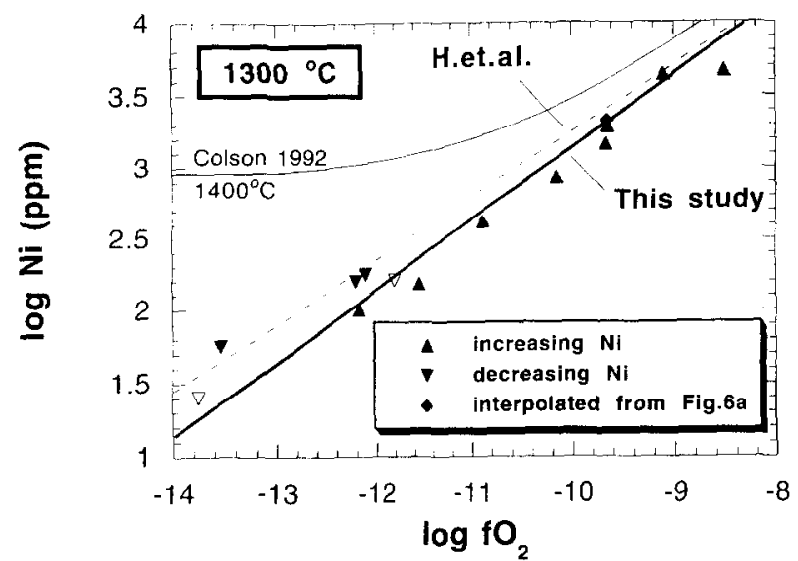

FIG. 5. Reversals of the equilibrium solubility of $\mathrm{Ni}$ in the investigated melt at $1300^{\circ} \mathrm{C}$, as a function of $f_{\mathrm{O}_{2}}$ from $10^{-8.5}$ to $10^{-13.75}$ The best fit line is drawn assuming a slope of 0.5 (all $\mathrm{Ni}$ as $\mathrm{Ni}^{2+}$ ) and has been constrained to satisfy also the solubility-temperature data (shown in Fig. 6). The line labelled " $\mathrm{H}$ et al." is calculated for a temperature of $1300^{\circ} \mathrm{C}$ from the fit to their data of HOLZHEID et al. (1994), for a Di-An eutectic melt. Closed symbols $=\mathrm{CO}-\mathrm{CO}_{2}$ mixtures; open symbols $=\mathrm{H}_{2} \mathrm{O}-\mathrm{H}_{2} \pm \mathrm{N}_{2}$ mixtures.

sults in erroneously high levels of the element sought. In the case of $\mathrm{Ni}$, a good example is provided by its determination in pallasitic olivines: REED et al. (1979) showed that ion microprobe analysis gave concentrations of

(a)
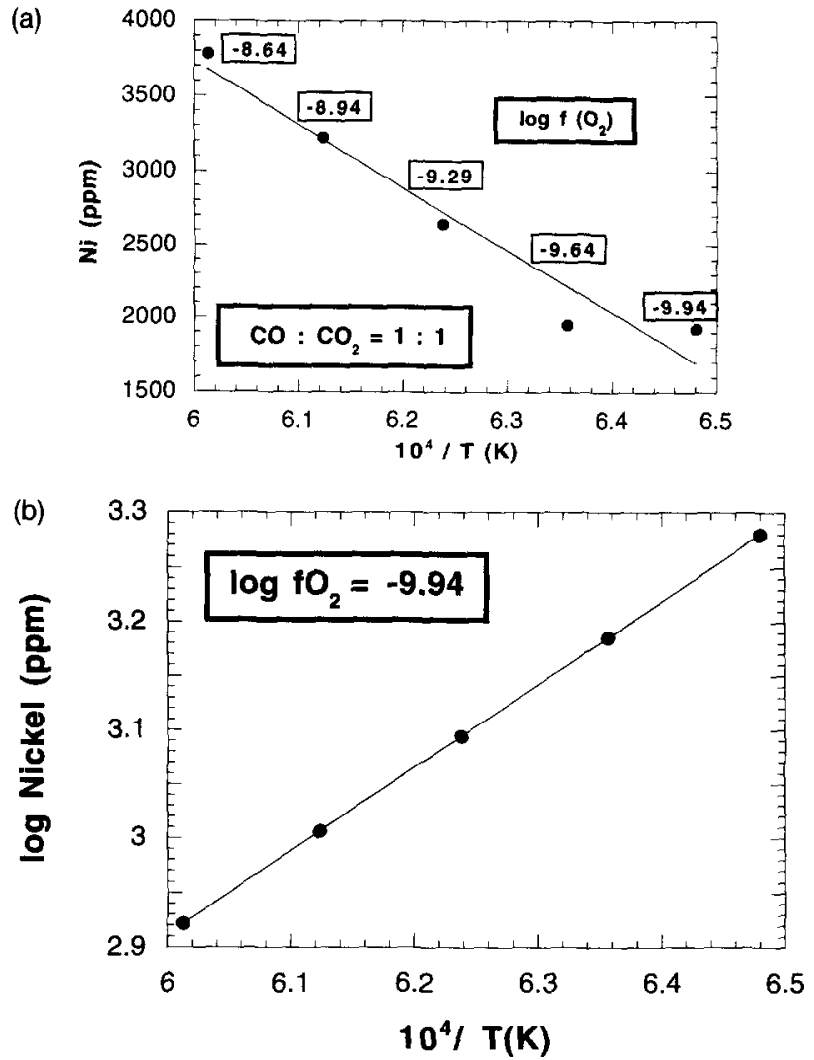

FIG. 6. (a) The temperature dependence of the solubility of $\mathrm{Ni}$ in the melt at a constant gas-mixing ratio of $\mathrm{CO} / \mathrm{CO}_{2}=1: 1$. (b) The calculated temperature dependence of solubility at a constant $f_{\mathrm{O}_{2}}$. 
22-41 ppm, considerably lower than the earlier electron microprobe analyses of $40-70 \mathrm{ppm}$ (although subsequent electron probe analyses by REED et al. (1979) were in agreement with the ion probe data.). In this study we have avoided this problem, since our samples are large enough for analysing using methods suitable for low levels, and we have checked one method against the other on the same samples. A potentially useful byproduct of the present experiments is that our samples could also make useful standards for microbeam techniques.

\section{SUMMARY}

We present a new experimental strategy for the determination of metal solubilities in silicate melts at conditions of controlled and variable temperature, $f_{\mathrm{O}_{2}}$, and composition. This method is extremely flexible. Composition, $f_{\mathrm{O}_{2}}$ and temperature can be changed in any direction. Sampling is simple and provides enough material for chemical analyses using methods well suited for the determination of low levels. The reversibility of equilibria may be unambiguously demonstrated by following the approach to a steady state in through a time series of samples. Our results for the solubility of $\mathrm{Ni}$ in a silicate melt disagree with previous determinations of the solubility of $\mathrm{Ni}$ in an anorthite-diopside melt at low $f_{\mathrm{O}_{2}}$ (COLSON, 1992) but agree with the results of HOLZHEID et al. (1994) on that melt composition.

Acknowledgments-We thank Anna Dietel, Detlef Krauße, Hubert Schulze, and Georg Hermannsdörfer for technical and analytical assistance. This study has been supported by DFG Schwerpunktprogramm "Experimentelle Studicn übcr Elcmentverteilung" grant Pa346/3-1. The manuscript has been improved by the comments of $\mathrm{K}$. Lodders and an anonymous reviewer.

Editorial handling: G. Faure

\section{REFERENCES}

BARIN 1. (1989) Thermochemical Data of Pure Substances, Vol. 1 and 2. $\mathrm{VCH}$, Weinheim, Germany.

CAPOBIANCO C. J. and AMELIN A. A. (1994) Metal-silicate partitioning of nickel and cobalt: The influence of temperature and oxygen fugacity. Goochim. Cosmochim. Acta 58, 125-140.

COLSON R. O. (1992) Solubility of neutral nickel in silicate melts and implications for the Earth's siderophile element budget. Nature $357,65-68$.

DINGWELL D. B. and VIRGO D. (1987) The effect of oxidation state on the of melts in the system $\mathrm{Na}_{2} \mathrm{O}-\mathrm{FeO}-\mathrm{Fe}_{2} \mathrm{O}_{3}-\mathrm{SiO}_{2}$. Geochim. Cosmochim. Acta 15, 195-205.

Dingwell D. B., O'Neill H. St.C., Palme H., and SPetrel B. (1993) The oxidation state of $\mathrm{Ni}$ in silicate melts at low $f_{\mathrm{O}_{2}}$. Eos 74,338 .

EhLers K., Grove T. D., Sisson T. W., RecCa S. I., and Zervas D. A. (1992) The effect of oxygen fugacity on the partitioning of nickel and cobalt between olivine, silicate melt, and metal. Gevchim. Cosmochim. Acta 56, 3733-3743.

Holzheid A., Borisov A., and PALme H. (1994) The effect of oxygen fugacity and temperature on solubilities of $\mathrm{Ni}, \mathrm{Co}$, and $\mathrm{Mo}$ in silicate melts. Geochim. Cosmochim. Acta 58, 1975-1981 (this issue).

HUEBNER J. S. (1987) Use of gas mixtures at low pressures to specify oxygen and other fugacities of furnace atmospheres. In Hydrothermal Experimental Techniques (ed. G. C. ULMER and H. L. BARNES), pp. 20-60. Wiley.

MORSE S. A., RHODES J. M., and NOLAN K. M. (1991) Redox effect on the partitioning of nickel in olivine Geochim Cosmochim Acta 55, 2373-2378.

O'Neill. H. St.C., Dingwell D. B., Palme H., and Spettel B. (1993) The solubility of Ir in silicate melts and Ir metal/melt distribution coefficients. Eos 74, 338.

O'Neill H. St.C., Dingwell D. B., Borisov A., Spettel B., and PAIMF H. (1994) Experimental petrochemistry of some highly siderophile elements at high temperatures, and some implications for core formation and the mantle's early history. Lithos (in press)

REED S. J. B., SCOTT E. R. D., and LoNG J. V. P. (1979) Ion microprobe analysis of olivine in pallasite meteorites for nickel. Earth Planet. Sci. Letl. 43, 5-12.

Sterle A. M., Colson R. O., Korotev R. L., and IIASkin L. A. (1992) Apollo 15 green glass: Compositional distribution and petrogenesis. Geochim Cosmochim Acta 56, 4075-4090. 